\title{
Influence of cellulose nanofibrils on the rheology, microstructure and strength of alkali activated ground granulated blast-furnace slag: a comparison with ordinary Portland cement
}

\author{
Hassan Ez-zaki (D) - Laura Riva • Maurizio Bellotto $\cdot$ Luca Valentini • \\ Enrico Garbin • Carlo Punta · Gilberto Artioli
}

Received: 21 July 2020/Accepted: 30 December 2020/Published online: 13 January 2021

(C) The Author(s) 2021, corrected publication 2021

\begin{abstract}
This paper reports on the effect of cellulose nanofibrils (CNFs) on the fresh-state properties of alkali activated ground granulated blast-furnace slag (GGBS). Surface functionalized (oxidized) CNFs were added to alkali activated GGBS water suspensions (hydraulic pastes). The rheological behaviour of the pastes was compared with OPC and interpreted based on the CNF-mineral surface interaction, and on the CNF-water interaction and swelling. The water dispersion of CNFs with different surface functionalization degrees resulted in gels of different viscosity and yield stress, due to their different hydrophilicity and water adsorption properties. On increasing the CNFs surface oxidation degree, the viscosity of the CNF water dispersion decreases and the CNF water adsorption increases, while the viscosity of fresh pastes increases because of the reduced amount of available mixing water. In the hardened state, the hydraulic pastes show differences in mechanical strength related to the type and the amount of CNF
\end{abstract}

H. Ez-zaki $(\bowtie) \cdot$ M. Bellotto · L. Valentini ·

E. Garbin - G. Artioli

CIRCe, Department of Geosciences, University of

Padova, Via G. Gradenigo 6, 35131 Padova, Italy

e-mail: hassan.ezzaki@unipd.it

L. Riva $\cdot$ C. Punta

Department of Chemistry, Materials, and Chemical Engineering "G. Natta" and INSTM Local Unit, Politecnico di Milano, Piazza Leonardo da Vinci 32, 20133 Milano, Italy influencing the porosity of the matrix as evidenced by the microstructural investigation performed by X-ray microtomography. The presence of higher amounts of CNFs induces the formation of porous agglomerates that may act as stress concentrators due to the swelling ability of nanofibrils.

Keywords Alkali activated slag · Cellulose nanofibrils · Rheology $\cdot$ Hydrophilic character . Oxidation degree $\cdot \mathrm{X}$-ray microtomography

\section{Introduction}

Alkali activated binders are actively researched since earlier than the half of last century as a possible alternative to Portland cement $[1,2]$. The interest in such materials spans from their higher resistance to acid corrosion and aggressive environmental conditions $[3,4]$ to reduced economic and environmental costs $[5,6]$. In the twenty-first century, the latter arguments have raised the interest on these materials, especially for the family of alkali activated binders produced from precursors constituted by industrial by-products, like blast furnace and steel slags. The replacement of Portland cement with alkali-activated ground granulated blast-furnace slag (GGBS) does not only reduce $\mathrm{CO}_{2}$ emissions, but is more economically viable and environmentally sustainable in terms of reduction of primary raw materials and of disposed waste. The 
efficiency, both technical and environmental, of the alkali activation can be limited depending on the composition of the slag and the type and concentration of the activator [7-9]. The use of alkali hydroxide or silicate solutions raises concerns about their corrosive properties and the related health and safety on the working sites [10]. Moreover, these alkaline solutions have high embedded energy and emission values, limiting the benefits of introducing the alkali activated binders [9, 11]. A suitable alternative to alkaline solutions is the use of solid alkali-activators such as sodium carbonate or sulphate because of their lower environmental impact and costs $[8,9,11]$. Despite their slow hardening and strength development, carbonate activators provided a successful performance in building and civil infrastructure projects over a long service life $[8,12]$. However, to allow the industrial use of sodium carbonate activated GGBS, it is necessary to verify the efficiency of the chemical admixtures, superplasticizers, viscosity modifiers, shrinkage and cracking reducers. It is known that superplasticizers are less effective in alkali activated binders, limiting their use in low porosity high strength concretes $[13,14]$. Therefore, an investigation on the effect of some specific cementitious viscosity modifiers on sodium carbonate activated GGBS can get considerable attention to assess their use in different industrial applications.

Various potential applications of cellulose nanofibrils (CNFs) in building materials have been proposed. Taking advantage of their properties, CNFs have shown a great potential as viscosity modifiers and reinforcing agents in cementitious materials $[15,16]$. On the other hand, one inherent problem of alkali activated binders is their low effectiveness towards viscosity modifiers. In this context we have evaluated the effect of the addition of CNFs to alkali activated materials, in comparison with the effects of the same addition to OPC, to assess the suitability of their use as viscosity modifiers or reinforcing agents.

Cellulose nanofibrils (CNFs) composed of crystalline and amorphous parts have been used to enhance the flexural strength and fracture toughness of cementitious materials $[17,18]$. Because of their distinctive advantages such as high Young's modulus (65-110 GPa) [19], large aspect ratio (4-20 nm width, 500-2000 nm length) [20], and thermal stability [21], CNFs allow an improvement in the mechanical properties such as elastic modulus, flexural and compressive strengths. Moreover, the use of CNFs can increase the degree of hydration, reduce the setting time and densify the microstructure when added to cement composites [17, 22-25].

Nanofibrillar cellulose suspensions may be obtained by the mechanical treatment of oxidized native cellulose, extracted from wood, plants and other cellulose sources. A common oxidative process is performed through 2,2,6,6 tetramethyl-1-piperidinyloxy (TEMPO) and $\mathrm{NaBr} / \mathrm{NaClO}$. This surface modification has been established to improve the solubility of cellulose by breaking the strong hydrogen bonds which keep the molecule rigid and insoluble [26-28]. The modified and functionalized surface of TEMPOoxidized cellulose nanofibrils (TOCNs) allows their dispersion in water almost as individual fibrils. The strong electrostatic repulsion between nanofibrils in water is due to the anionically charged functional groups introduced on the TOCNs surfaces [26, 29].

The rheology of dispersed CNFs depends on the conditions and equipment used during the mechanical defibrillation [29-31]. Some studies [29, 32, 33] noted that the viscosity of dispersed CNFs in water was different depending on the oxidation degree and on the disintegration method (magnetic stirring, processing with a household mixer or with an ultrasonic homogenizer). The time needed to achieve the maximum nanofiber yield was notably different for these processes. Previous research [30] has investigated the degree of dispersion of CNFs in water as a function of the stirring time. The dispersions behaved as a yield stress and shear thinning fluid. In addition to shear thinning, some TEMPOoxidized celluloses showed a thixotropic behaviour [31] as a function of the chosen disintegration method. Saito et al. [34] described the relationship between the dispersion of CNFs and the amount of carboxylate groups. A high density of carboxylate groups increases the electrostatic repulsion between nanofibrils. Therefore, the modified surface of CNFs may significantly alter the cement particle interactions.

In a fresh slurry, the interactions of cement particles are attributed to surface forces such as Van der Waals (V.d.W), electrostatic repulsion, hydrogen bonding and correlation forces, and/or surface contacts such as friction or collisions at very low water/solid ratio $(\mathrm{w} / \mathrm{s})$ [35-38]. CNFs have been previously proposed as a reinforcing agent in cementitious materials and can alter the rheological properties. An increase of viscosity is observed on increasing the CNF amount 
in cement slurries. This effect is due to the ability of CNFs to adsorb water molecules, thus thickening the fresh cement slurry $[17,22,23,38,39]$. The hydrophilic character, the capacity to attract water molecules and create hydrogen bonding [40], of CNFs can reduce the autogenous shrinkage of the cement slurry by increasing the mixing water retention during cement hydration. Syneresis and bleeding is also reduced. Some authors [41-43] mentioned that the high alkalinity of cementitious medium can hydrolyse the fibres and hence decrease their reinforcement capacity. CNF can be safely used as viscosity modifiers, although their reinforcing properties need further testing in order to assess any possible durability issues.

Other than the nanofibril surface charge induced by the modification of cellulose surface by oxidation, the dispersion degree of CNFs is of crucial importance when adding them to cement. If the fibrils are not entirely dispersed, they can cause aggregation, increasing viscosity and leading to the formation of pores in the hardened structure. However, a successful use of CNFs can improve the degree of hydration of cement slurries by increasing the nucleation rate and the mechanical strength and can affect the setting time and the microstructure [17]. For GGBS, no previous work has been found to describe their rheological properties under the effect of CNFs.

The objectives of this paper are to investigate the influence of cellulose nanofibrils (CNFs) on the rheological properties of alkali activated ground granulated blast-furnace slag (AAS) matrix and to compare it with ordinary Portland cement (OPC) considering different degrees of oxidation for the CNF. Moreover, the interactions between functionalized (carboxylate groups) surface of CNFs and the particle surface of GGBS/OPC were evaluated in order to analyse their effect on the rheology, microstructure and strength of different pastes. The influence of CNF on the heat of hydration, microstructure and mechanical performance was also examined.

\section{Materials and methods}

\subsection{Materials}

The raw materials used for this study include Ordinary Portland Cement (OPC) CEM I 52.5-R, ground granulated blast-furnace slag (GGBS) with the composition and particle size distributions reported in Table 1, and two different TEMPO-oxidized cellulose nanofibrils (CNFs) extracted from linters: LR17 and LR19 with an oxidation rate of $0.86 \mathrm{mmol}_{\mathrm{COOH}} /$ $\mathrm{g}_{\mathrm{TOCNF}}$ and $1.90 \mathrm{mmol}_{\mathrm{COOH}} / \mathrm{g}_{\mathrm{TOCNF}}$ respectively. CNFs exhibit a highly dense network structure composed of twisted and entangled nanofibrils.

Figure 1 shows the ATR-IR spectra and XRD patterns of CNFs. ATR-IR spectra were recorded by using a Nicolet 6700 FT-IR spectrometer (Thermo Fisher Scientific, America). Sixteen scans were averaged at a resolution of $4 \mathrm{~cm}^{-1}$. The spectra were subject to ATR (attenuated total reflection) correction, smoothing and baseline correction and normalization. Each spectrum was recorded in the $4000-800 \mathrm{~cm}^{-1}$ wavenumber range. In the ATR-IR spectra (Fig. 1a), the $3340 \mathrm{~cm}^{-1}$ band is assigned to $\mathrm{O}-\mathrm{H}$ stretching, which is related to the amount of water in the cellulose structure. Sample LR19 with higher oxidation degree coordinates more water with an intense peak at $3340 \mathrm{~cm}^{-1}$. The peak at $2900 \mathrm{~cm}^{-1}$ is attributed to the cellulose $\mathrm{C}-\mathrm{H}$ stretching and it is of equivalent

Table 1 Chemical composition and particle size distributions of raw materials

\begin{tabular}{lcr}
\hline Oxide $(w t \%)$ & OPC & GGBS \\
\hline $\mathrm{Na}_{2} \mathrm{O}$ & 1.18 & 0.22 \\
$\mathrm{MgO}$ & 3.07 & 7.41 \\
$\mathrm{Al}_{2} \mathrm{O}_{3}$ & 5.50 & 10.70 \\
$\mathrm{SiO}_{2}$ & 19.43 & 36.23 \\
$\mathrm{P}_{2} \mathrm{O}_{5}$ & 0.17 & 0.01 \\
$\mathrm{SO}_{3}$ & 3.18 & 1.03 \\
$\mathrm{Cl}$ & 0.05 & - \\
$\mathrm{K}_{2} \mathrm{O}$ & 0.39 & 0.45 \\
$\mathrm{CaO}$ & 60.76 & 40.92 \\
$\mathrm{TiO}_{2}$ & 0.25 & 0.68 \\
$\mathrm{Cr}_{2} \mathrm{O}_{3}$ & - & 0.01 \\
$\mathrm{MnO}$ & 0.12 & 0.27 \\
$\mathrm{Fe}_{2} \mathrm{O}_{3}$ & 1.80 & 0.72 \\
$\mathrm{ZnO}_{\mathrm{SrO}}$ & 0.03 & 0.01 \\
$\mathrm{PrO}_{2}$ & 0.08 & 0.07 \\
$\mathrm{D}_{10}$ & & \\
$\mathrm{D}_{50}$ & 2.3 & 2.2 \\
$\mathrm{D}_{90}$ & 12.5 & 11.3 \\
\hline
\end{tabular}



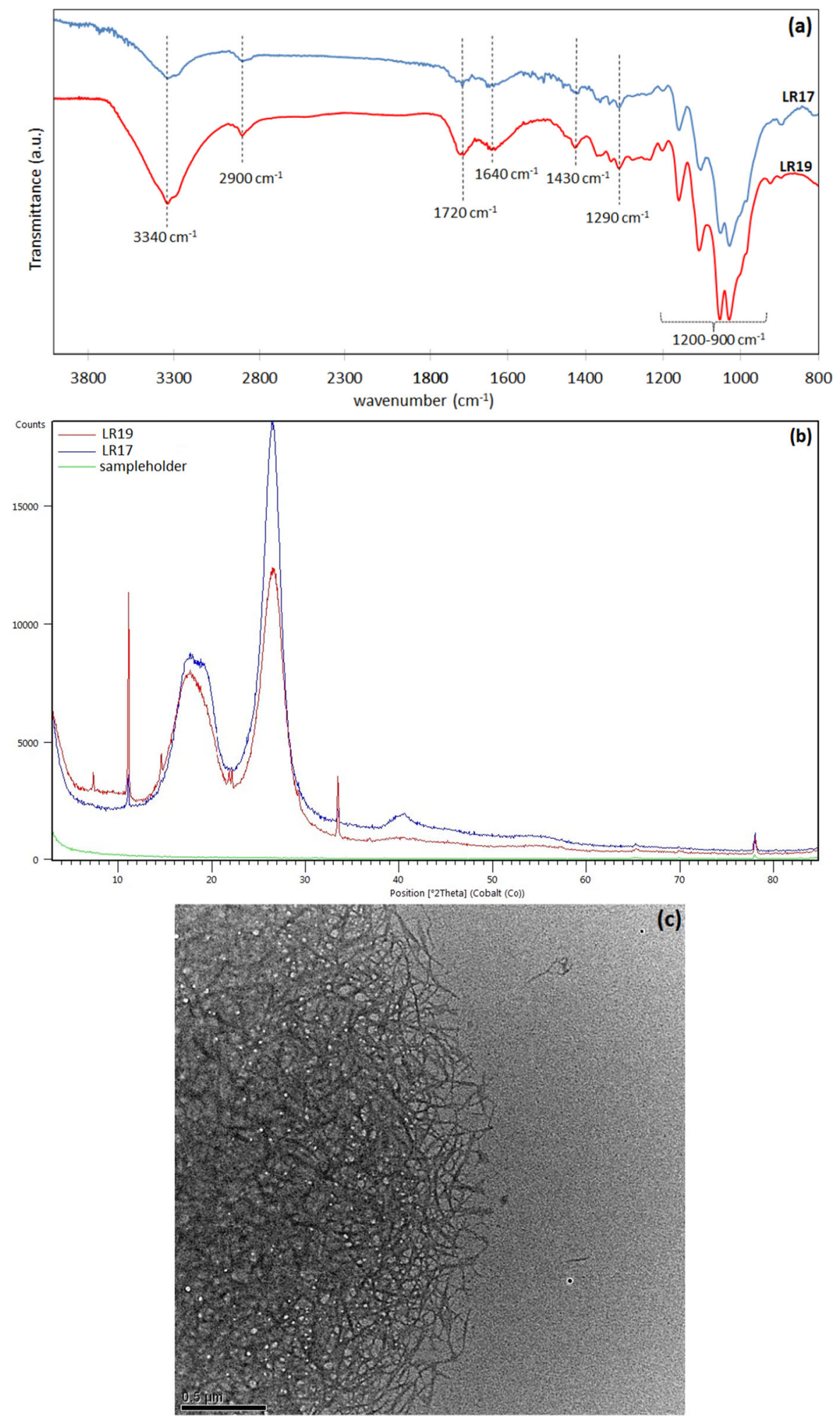

Fig. 1 ATR-IR (a), XRD patterns (b) and TEM image (c) of CNFs 
intensity in the two samples, while the peak at $1430 \mathrm{~cm}^{-1}$ is due to the bending vibration of carboxylic and cellulose $\mathrm{O}-\mathrm{H}$ groups and its intensity is lower for LR17 because of its lower density of carboxylic groups. Sample LR17, with a lower oxidation degree, has the carboxylic $\mathrm{C}=\mathrm{O}$ stretching band of lower intensity, both in its acidic form at $1720 \mathrm{~cm}^{-1}$ and in its neutralized form (the soap COONa) at $1640 \mathrm{~cm}^{-1}$. The peak at $1290 \mathrm{~cm}^{-1}$ related to the bending of $\mathrm{OH}$ group is more pronounced in LR19 with higher oxidation degree. The complex signal at $1200-900 \mathrm{~cm}^{-1}$ is associated to the vibration of the cellulose skeletal rings and to the $\mathrm{C}-$ $\mathrm{O}-\mathrm{C}$ bridge stretchings.

X-ray diffraction data were recorded with a X'Pert Pro diffractometer (Malvern Panalytical, UK) equipped with a $\mathrm{Cu}$ X-ray tube operating at $40 \mathrm{kV}$ and $40 \mathrm{~mA}$, and an $\mathrm{X}^{\prime}$ Celerator detector. The XRD patterns have been measured in the $3^{\circ}-85^{\circ} 2 \vartheta$ range. Both CNFs show three diffraction peaks of crystalline cellulose at $2 \vartheta=11.1^{\circ} ; 26.6^{\circ} ; 33.5^{\circ}$ and a diffraction band at 29 between $15^{\circ}$ and $20^{\circ}$ which is attributed to amorphous cellulose (Fig. 1 b). The relative intensity of the reflections attributed to crystalline cellulose is different in the two samples, suggesting that the oxidation process has influenced the fibril orientation and alignment.

The Crystallinity Index (CI) for each sample was determined by measuring the area of all crystalline peaks to the total area $[44,45]$. The $C_{I}$ of LR17 and LR19 are $67 \%$ and 56\%, respectively. LR19 has a lower $C_{I}$, due to the stronger chemical oxidation process which contributes to the degradation of crystalline cellulose $[46,47]$.

The morphology of CNFs was examined by using a TEM (Transmission Electron Microscope Philips CM 200, Koninklijke Philips N.V., Amsterdam, Netherlands) with an acceleration voltage of $200 \mathrm{kV}$. LR17 and LR19 showed substantially similar shape and size from TEM observations. The typical microstructure of oxidised and defibrillated nancellulose (Fig. 1 c) displays twisted and entangled nanofibrils. As-received, CNFs have an average length in the range of 200-400 nm and a width of about $10 \mathrm{~nm}$.

\subsection{Methods}

Dry cellulose nanofibrils were dispersed in deionized water to obtain dispersed suspensions of $0.02,0.5$ and
$2 \mathrm{wt} \%$ using an IKA ULTRA TURRAX Tube Drive mixer for $10 \mathrm{~min}$, followed by ultrasonic treatment (Elmasonic $\mathrm{S} 30 \mathrm{H}$ ) for $10 \mathrm{~min}$.

The viscosity of the water dispersions of the CNFs was measured with a stress-controlled rheometer Anton Paar MCR92 equipped with a cone-plate geometry, $50 \mathrm{~mm}$ in diameter. The temperature has been controlled to $20 \pm 0.1{ }^{\circ} \mathrm{C}$, and evaporation of water has been avoided thanks to a solvent trap. The flow curves have been measured with a triangular procedure and logarithmic ramps of shear rate from $10^{-4}$ to $10 \mathrm{~s}^{-1}$ and back allowing $5 \mathrm{~s}$ measuring time per point. The ramp up was immediately followed by the ramp down.

To prepare the hydraulic pastes, GGBS was blended with equimolar amounts of $\mathrm{Ca}(\mathrm{OH})_{2}$ and $\mathrm{Na}_{2} \mathrm{CO}_{3}$ (91.5:3.5:5.0 wt\%) to achieve a higher $\mathrm{pH}$ than achievable with $\mathrm{Na}_{2} \mathrm{CO}_{3}$ alone $(\geq 13.5)$, thus accelerating the slag dissolution, promoting the precipitation of $\mathrm{C}-(\mathrm{N})-\mathrm{A}-\mathrm{S}-\mathrm{H}$ type gel and thus causing setting [48]. The use of sodium carbonate can also contribute to enhanced fresh state properties and mitigate the environmental impact of the production of the alkaline activators as it has a very low $\mathrm{CO}_{2}$ footprint and energy consumption, e.g. 97\% lower than common activators [11, 49].

In a typical hydraulic paste preparation for the rheological testing, $5 \mathrm{~g}$ of solid, either OPC or alkali activated GGBS, were placed in the ULTRA TURRAX Tube Drive mixer along with deionized water or the CNF suspension. The paste was mixed for $3 \mathrm{~min}$ at $1700 \mathrm{rpm}$ in order to wet all solid particles and to eliminate any air bubbles. The water to solid ratio (w/ s) was $0.3,0.35,0.4,0.45$ and 0.5 for the control formulations without CNFs, while the pastes with CNFs were prepared at the w/s of 0.5. CNFs were introduced in the hydraulic pastes as water dispersions, and the samples are named after the concentration of the CNF dispersion used. For example, sample OPC002LR17 represents an OPC paste prepared with w/s 0.5 and batched with the LR17 CNF dispersion containing $0.02 \mathrm{wt} \%$ CNF. In Table 2, all the formulations prepared are summarized.

The rheological measurements of the hydraulic pastes were performed with a stress-controlled rheometer Anton Paar MCR92 equipped with a serrated plate-plate geometry, with a stationary lower plate (diameter $50 \mathrm{~mm}$ ) and a rotating upper plate $25 \mathrm{~mm}$ in diameter. The gap has been set to $2 \mathrm{~mm}$, the 
Table 2 Formulation of samples with dispersed cellulose nanofibrils (CNFs)

\begin{tabular}{llll}
\hline Formulation & Sample ID & CNF (wt\%) & W/S \\
\hline Control & OPC & - & $0.3-0.5$ \\
OPC-LR17 & OPC002LR17 & 0.02 & 0.5 \\
& OPC05LR17 & 0.5 & 0.5 \\
& OPC2LR17 & 2 & 0.5 \\
OPC-LR19 & OPC002LR19 & 0.02 & 0.5 \\
& OPC05LR19 & 0.5 & 0.5 \\
& OPC2LR19 & 2 & 0.5 \\
Control & GGBS & - & $0.3-0.5$ \\
GGBS-LR17 & GGBS002LR17 & 0.02 & 0.5 \\
& GGBS05LR17 & 0.5 & 0.5 \\
& GGBS2LR17 & 2 & 0.5 \\
GGBS-LR19 & GGBS002LR19 & 0.02 & 0.5 \\
& GGBS05LR19 & 0.5 & 0.5 \\
& GGBS2LR19 & 2 & 0.5 \\
\hline
\end{tabular}

temperature has been controlled to $20 \pm 0.1^{\circ} \mathrm{C}$, and evaporation of water has been avoided thanks to a solvent trap. The flow curves have been measured with a triangular procedure and logarithmic ramps of shear rate from $10^{-4}$ to $10 \mathrm{~s}^{-1}$ and back allowing $5 \mathrm{~s}$ measuring time per point. The ramp up was immediately followed by the ramp down. The measurements have been preceded by a pre-shear and structure recovery. The pre-shear has been performed in oscillation, with a high amplitude oscillation of $10 \%$ strain amplitude at frequency $10 \mathrm{~Hz}$ for $60 \mathrm{~s}$. The structure recovery has been performed in low amplitude oscillation with $0.0005 \%$ strain amplitude at frequency of $1 \mathrm{~Hz}$ for $120 \mathrm{~s}$.

To examine the effect of CNFs on the hydration kinetics of OPC and alkali-activated GGBS, semiadiabatic calorimetry measurements have been performed on hydraulic pastes with w/s 0.5 . The reference control measurements have been batched with water while the CNFs have been introduced as $2 \mathrm{wt} \%$ water dispersions. The temperatures have been measured with an 8-line multiplexer using type $\mathrm{K}$ Omega thermocouples (Norwalk, US). The calorimeter was calibrated by measuring the heat transfer coefficient and the sample heat capacity, and deriving the heat released during the reaction and the heat flux per sample unit mass [50].
The 3D microstructural details of the hydrated samples were obtained by X-ray microtomography imaging using a Skyscan 1172 (Bruker, Billerica-US) instrument. After the compressive strength tests, approximately undamaged cubic $(15 \times 15 \times 15 \mathrm{~mm})$ fragments of the samples were irradiated with a polychromatic $\mathrm{W}$ radiation $(100 \mathrm{kV}$ source voltage, $100 \mu \mathrm{A}$ source current), filtered with a $0.5 \mathrm{~mm}$ thick aluminium foil. For each sample, 1200 projections were acquired by a CCD detector of $4000 \times 2664$ pixels $(2 \times 2$ camera binning $)$ with an exposure time of $0.9 \mathrm{~s}$. Cross-sectional slices, having a pixel size of $11 \mu \mathrm{m}$, were reconstructed using the FDK algorithm [51] and subsequently converted to binary images in which white pixels represent low attenuation features such as air voids and nanocellulose agglomerates. Additional details of the image processing procedure are reported elsewhere [50, 52].

In order to estimate the cumulative volume of air voids and CNF aggregates, the reconstructed sectional images were processed with the software Fiji [53] to calculate the pore volume in the bulk structure. The grayscale is converted to binary images by applying the automated thresholding algorithm of Huang [42], followed by reduction of noise and artifacts to enhance the definition of the object's edges. More details on the processing method are mentioned in [52, 54].

The compressive tests on OPC and alkali-activated GGBS with water or dispersed CNFs (0.5 and $2 \mathrm{wt} \%)$ were performed on prismatic specimens $(15 \times 15 \times 60 \mathrm{~mm})$ using a Universal Bench Top testing machine (Galdabini, Varese-Italy) with a fullscale of 25,000 $\mathrm{N}$ and an accuracy of $0.03 \%$. The paste prisms were prepared with $\mathrm{w} / \mathrm{s}=0.5$ and stored in a humid chamber $(95 \%)$ at $21 \pm 1{ }^{\circ} \mathrm{C}$ until the mechanical tests at 7 and 28 days. The size of the specimens, which is about 19 times smaller than the $40 \times 40 \times 160 \mathrm{~mm}$ of EN 196-1 [55], was a tradeoff between CNFs availability for the pastes and representativeness of results. The tests were performed with a scaled in-house designed test rig suited to compress a cubic volume of paste of $15 \times 15 \times 15 \mathrm{~mm}$ according to a testing procedure similar to EN 196-1 [55]. The loading rate was of $160 \mathrm{~N} / \mathrm{s}$. The average of four values is reported with the related standard deviation error bars of each paste. According to [56], the recorded compressive strengths might be about $19 \%$ larger than those obtainable via EN 196-1 [55] specimens. 
The paste mixing procedure for the calorimetric and strength experiments was similar to the paste mixing for the rheological experiments, mixing larger quantities of materials in a mechanical stirrer with a turbine blade. Mixing was performed at $400 \mathrm{rpm}$ for $3 \mathrm{~min}$.

\section{Results and discussions}

\subsection{Rheological properties}

In this study, only the ramp down data was analysed and the curves were plotted on a logarithmic scale for better illustration of the values at low shear ranges.

\subsubsection{Rheological properties of dispersed CNFs in water}

Viscosity of different CNFs water dispersions is presented in Fig. 2. From these data, yield stress $\left(\tau_{y}\right)$ is measured as the minimum of the shear stress. The flow curves have been modelled with the Carreau equation, reported in Eq. 1, which describes the viscosity of a shear thinning fluid as a function of shear rate. In the Carreau model, three separate regions are described: in the first one at low shear rate, the fluid shows a Newtonian behaviour described by the zero shear viscosity $\eta_{0}$. This region ends at a shear rate equal to the inverse of the characteristic relaxation time $\lambda$ of the system, related to the fibril aggregation in our case. The second region shows a shear-thinning behaviour where the viscosity decreases following a power law model described by the exponent $N$, finally reaching in the third region a novel Newtonian behaviour at high-shear-rate, defined by the infinite shear viscosity $\eta_{\infty}[57,58]$. In our data we do not observe the low shear rate Newtonian plateau, an indication that the relaxation time associated to the fibril aggregation process is larger than the inverse of the lowest experimental shear rate. We have thus chosen arbitrarily for all measurements a relaxation time of $1.00 \times \operatorname{ssss} 10^{6} \mathrm{~s}$, two orders of magnitude higher than the inverse of the minimum experimental shear rate. The plotted viscosity curves shown in Fig. 2 are adequately modeled by the Carreau equation (Eq. 1).

$\eta=\eta \infty+\frac{\eta 0-\eta \infty}{\left[1+\left(\lambda \gamma^{\prime}\right)^{2}\right]^{N}}$
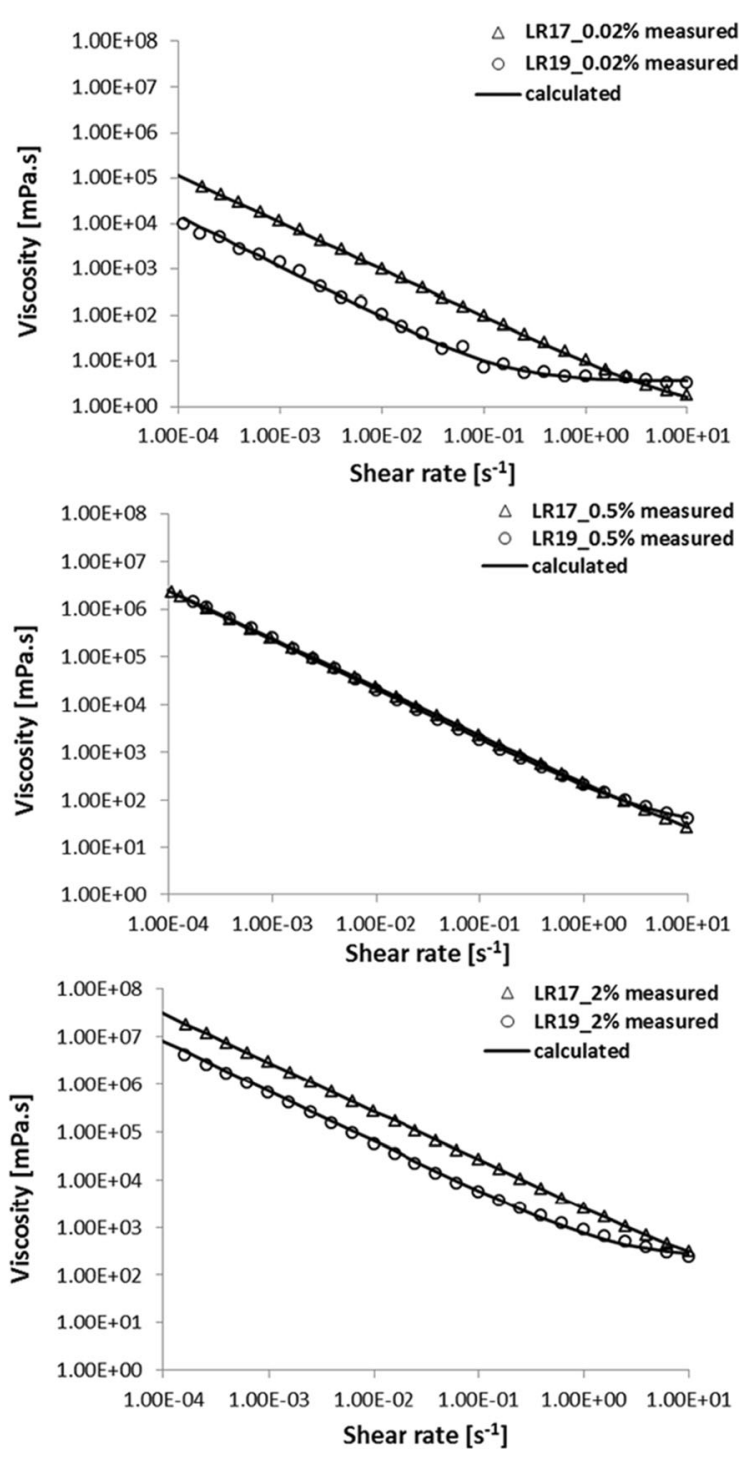

Fig. 2 Experimental data and calculated viscosity by Carreau model of dispersed CNFs in water

In Table 3, the yield stress values along with the fitted parameters of the Carreau model are reported. It may be observed that the relative trends of the yield stress and of $\eta_{0}$ are the same, pointing to the fact that they express the same physical property of the suspensions. The yield stress or $\eta_{0}$ describes the stress which must be exerted to break up the rest structure of the dispersion and start flow, or alternatively the energy dissipation which must be provided to sustain the low shear rate flow. So, they are a function of interparticle forces. The LR17 CNF has higher values suggesting that it is characterized by higher inter-fibril 
Table 3 Yield stress $\tau_{y}$ and fitted parameters of the Carreau model of dispersed CNFs in water

\begin{tabular}{llllll}
\hline CNFs & $(\mathrm{wt} \%)$ & $\tau_{\mathrm{y}}(\mathrm{Pa})$ & $\eta_{0}(\mathrm{mPa} \mathrm{s})$ & $\mathrm{N}$ & $\eta_{\infty}(\mathrm{mPa} \mathrm{s})$ \\
\hline LR17 & 0.02 & $1.00 \times 10^{-2}$ & $1.31 \times 10^{7}$ & $5.15 \times 10^{-1}$ & $8.45 \times 10^{-1}$ \\
& 0.5 & $2.20 \times 10^{-1}$ & $2.57 \times 10^{8}$ & $5.05 \times 10^{-1}$ & $5.15 \times 10^{0}$ \\
& 2 & $2.58 \times 10^{0}$ & $3.32 \times 10^{9}$ & $5.10 \times 10^{-1}$ & $6.98 \times 10^{1}$ \\
LR19 & 0.02 & $7.00 \times 10^{-4}$ & $2.54 \times 10^{6}$ & $5.58 \times 10^{-1}$ & $3.69 \times 10^{0}$ \\
& 0.5 & $1.80 \times 10^{-1}$ & $2.88 \times 10^{8}$ & $5.18 \times 10^{-1}$ & $2.67 \times 10^{1}$ \\
& 2 & $5.30 \times 10^{-1}$ & $1.00 \times 10^{9}$ & $5.24 \times 10^{-1}$ & $2.38 \times 10^{2}$ \\
\hline
\end{tabular}

forces and stronger fibril agglomerates. On the contrary, $\eta_{\infty}$ describes the viscosity of the dispersion when the fibrils have reached their maximum state of de-aggregation. So, it is a function of the volume fraction of the fibrils since in a suspension viscosity is a function of the solid volume fraction as described by the Einstein [59] and Krieger-Dougherty [60] models. The LR19 has higher values suggesting that it is characterized by more swollen fibrils, or fibrils which have more adsorbed water. So, it appears that CNF LR17, with a lower oxidation degree, is characterized by stronger inter-fibril attractive interactions, coming from the smaller electrostatic repulsion compared to LR19, associated to the smaller density of surface anionic carboxylic groups. On the other hand, the CNF LR19, with a larger surface density of carboxylic groups, is capable of adsorbing more water and swelling more than LR17. This can confirm the hypothesis of high swelling ability of CNF described by Belea et al. [38]. The behaviour of nanofibrils in a range of large shear-rates can be described in a simplified schematic diagram in Fig. 3.

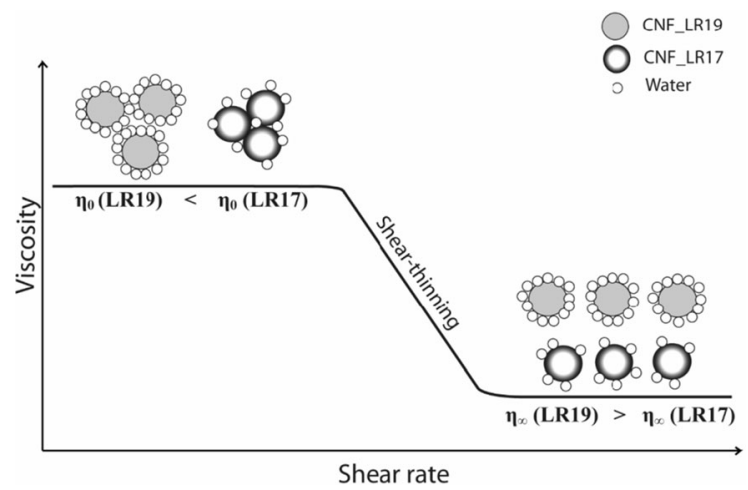

Fig. 3 Schematic diagram for different flocs under large-shearrate range

\subsubsection{Rheological properties of OPC and GGBS with different $w / s$ ratios}

Different pastes were prepared without any additives to establish the effect of $\mathrm{w} / \mathrm{s}$ on the rheological properties. The flow curves are shown in Fig. 4. Both OPC and alkali activated GGBS pastes show a shear thinning, power law behaviour at all $\mathrm{w} / \mathrm{s}$ as shown in Fig. $4 \mathrm{~b}, \mathrm{~d}$. The relation between yield stress, measured as the minimum shear stress in Fig. 4a, c, and the solid volume fraction $\phi$ of the pastes characterizes their microstructure and is related to the fractal dimension of the binder particle agglomerates [61]. This relation is reported in Fig. 5 for OPC and alkali activated GGBS and illustrates the difference between the two, stemming from differences in the surface interaction forces.

The rheological response of GGBS activated with the use of sodium carbonate was found to be characterized by a lower yield stress and viscosity compared to OPC, except at the highest fraction (Fig. 5). Based on the results of previous studies $[11,62,63]$, it is reported that one of the major limitations of using AAS as a sustainable material is due to its high viscosity caused by common alkali activators (such as sodium silicate, sodium hydroxide, etc.). The sodium carbonate used for the alkali activation of GGBS showed similar results as obtained from OPC (Figs. 4, 5) confirming its suitability as an alternative for the alkaline activator solutions.

\subsubsection{Effect of CNFs on rheological properties of CEM and GGBS pastes}

Figure 6 shows the experimental flow curves for OPC and GGBS pastes with different CNFs. The behaviour is shear thinning for all samples, with viscosity and yield stress increasing on increasing the dosage of CNFs both in OPC and GGBS. Yield stress is 

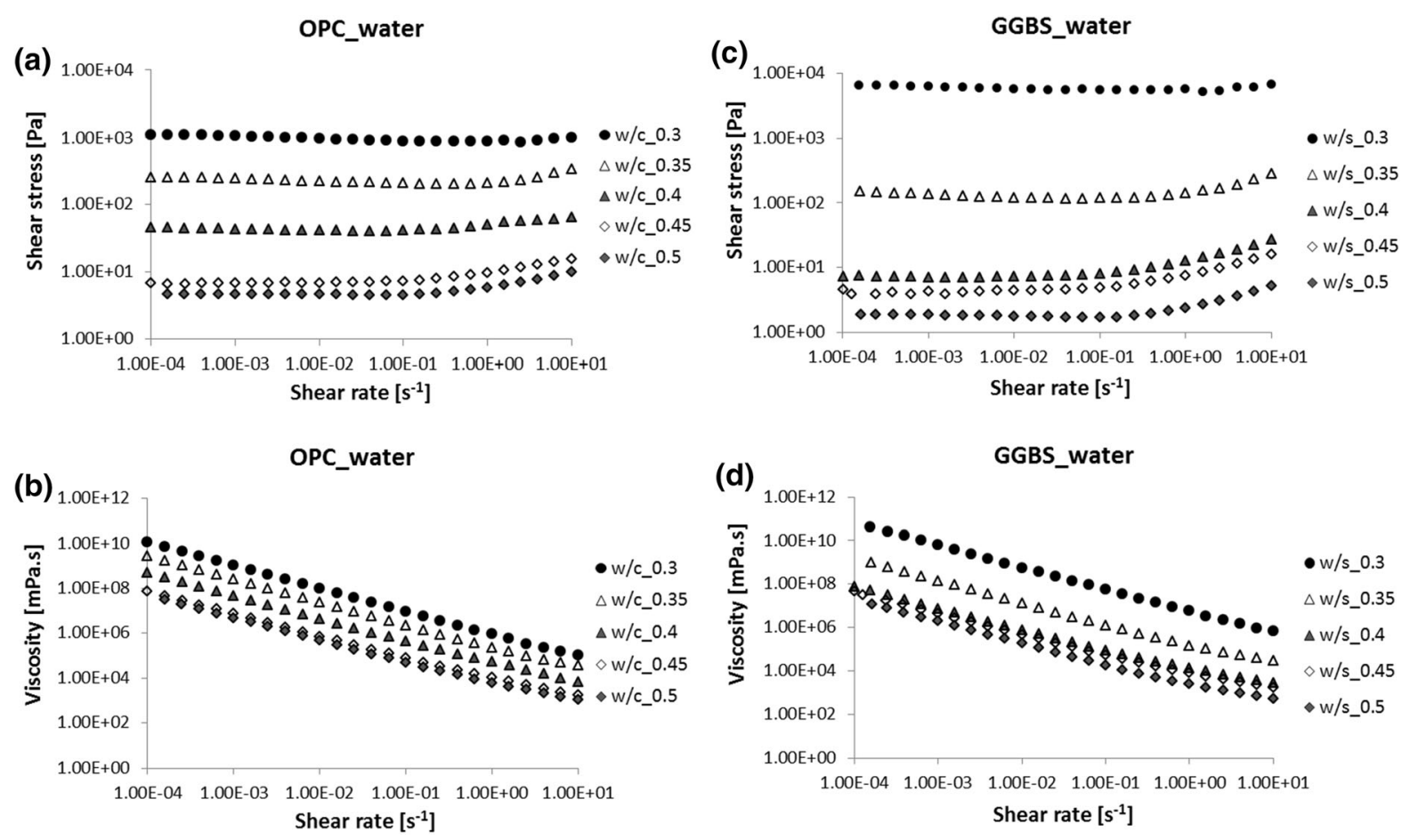

Fig. 4 Flow curves and viscosity curves of OPC (a-b) and GGBS (c-d) with different w/s ratios

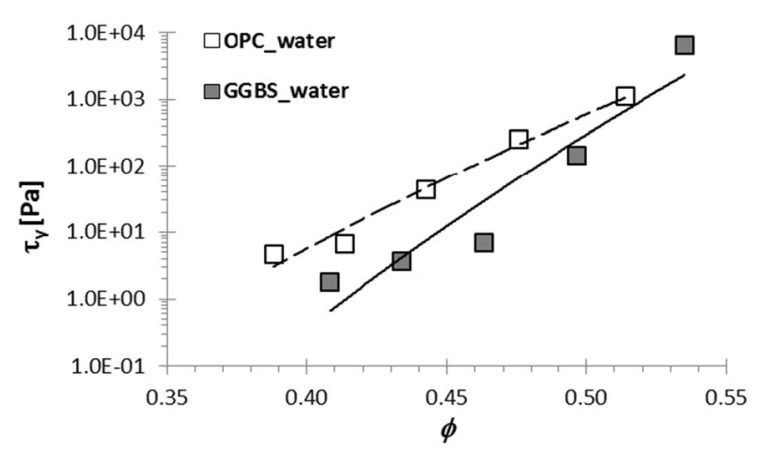

Fig. 5 Illustration of yield stress $\left(\tau_{y}\right)$ versus solid volume fraction $(\phi)$ of OPC and GGBS suspension

calculated as the minimum of the stress versus shear rate curves, and the values are reported in Table 4.

The results obtained in Table 4 and Fig. 6 indicate a strong dependence of the rheological properties on the CNF fraction rather than on the cementitious system type (AAS and OPC). At low CNFs fractions, $0.02 \mathrm{wt} \%$ and $0.5 \mathrm{wt} \%$, LR17-OPC and -GGBS showed viscosity curves similar to those of the reference pastes (Fig. 6c, g). On the contrary, the dosage of $0.5 \mathrm{wt} \%$ LR19 in the slurries showed a significantly higher viscosity than the OPC and GGBS without CNF (Fig. 6d, h). The higher viscosity of pastes with LR19 can be clearly seen at the highest CNF fraction (2wt\%). The higher viscosity of the pastes including LR19 results also in higher yield stress values, as reported in Table 4 . The difference in the rheological properties can be related to the higher oxidation degree of CNFs: $1.90 \mathrm{mmol}_{\mathrm{COOH}} / \mathrm{g}_{\mathrm{TOCNF}}$ for LR19 versus $0.86 \mathrm{mmol}_{\mathrm{COOH}} / \mathrm{g}_{\mathrm{TOCNF}}$ for LR17. We have seen in the previous paragraph how a higher oxidation degree can increase the fluidity of CNF water dispersions by increasing the surface charge and thus increasing of electrostatic repulsions between nanofibrils. However, the hydrophilic properties of high oxidation degree-CNF increased the viscosity of fresh OPC and GGBS pastes by swelling and adsorbing larger amounts of water on its surface thus reducing the amount of mixing water in the slurries. A similar effect has been reported by Ousmane et al. [42] using a new type of nanocellulose in concrete technology. 

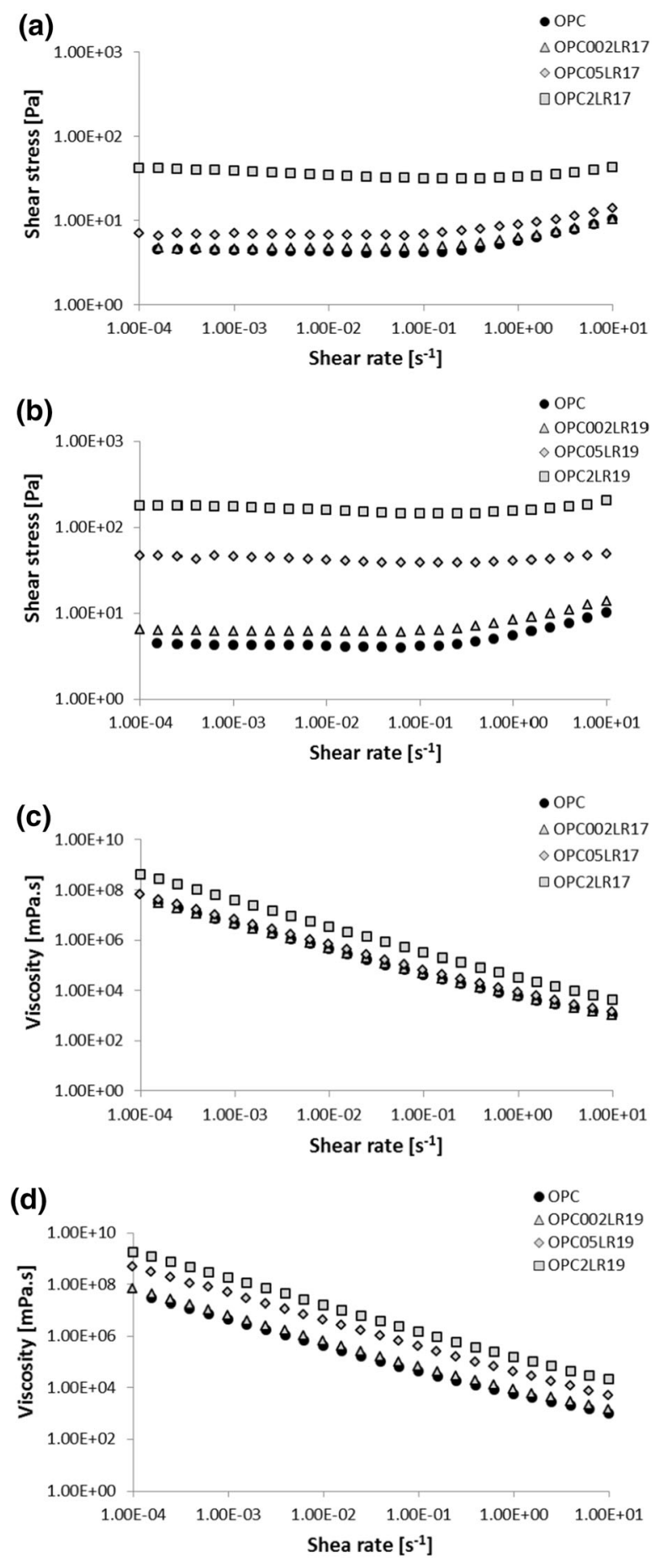
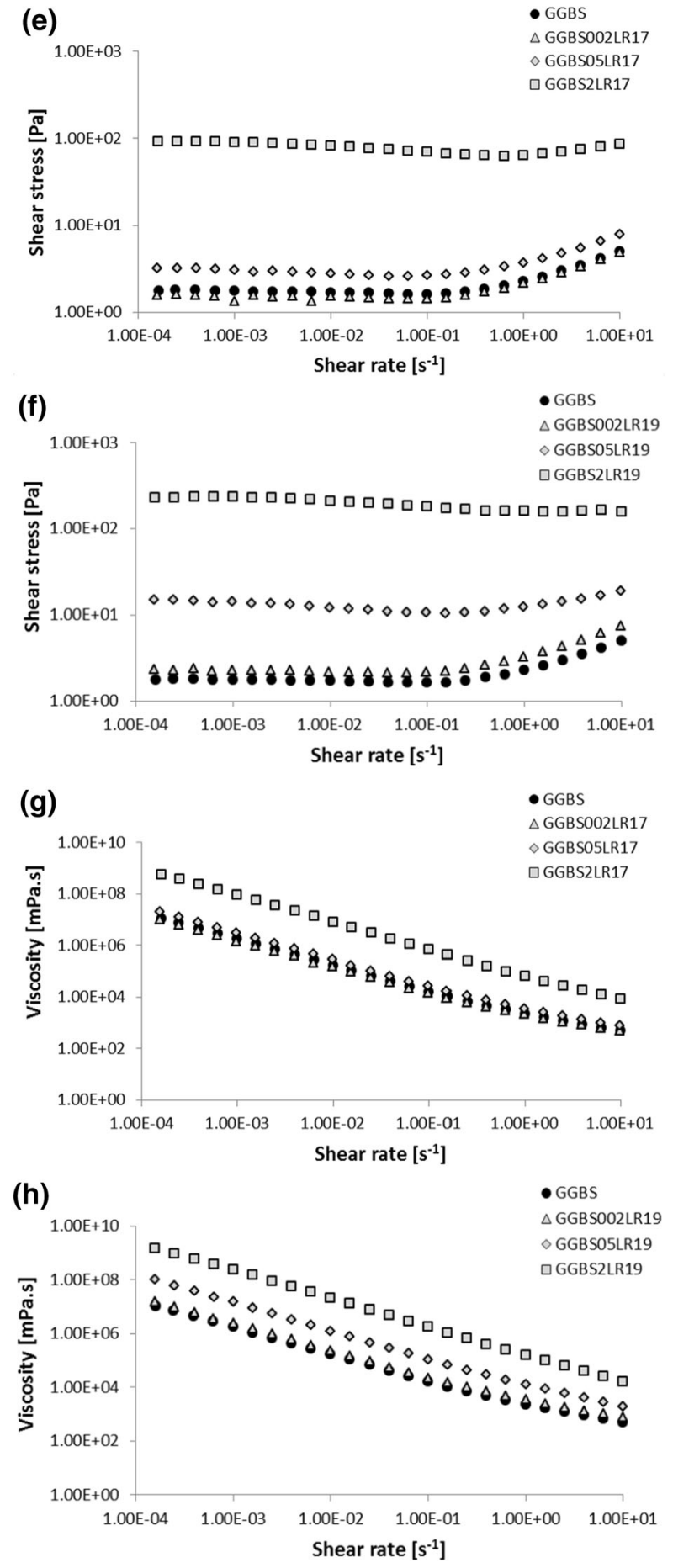

Fig. 6 Flow curves and viscosity curves of $\mathbf{a}-\mathbf{d}$ OPC and $\mathbf{e}-\mathbf{h}$ GGBS with different amounts of CNFs 
Table 4 Yield stress (Pa) of OPC and GGBS pastes with different CNFs

\begin{tabular}{llll}
\hline Paste & CNF $(\%)$ & OPC $(\mathrm{Pa})$ & GGBS $(\mathrm{Pa})$ \\
\hline Control & 0 & 4.03 & 1.61 \\
LR17 & 0.02 & 4.54 & 1.34 \\
& 0.5 & 6.59 & 2.64 \\
& 2 & 30.76 & 62.34 \\
LR19 & 0.02 & 6.01 & 2.07 \\
& 0.5 & 38.08 & 10.26 \\
& 2 & 147.15 & 157.02 \\
\hline
\end{tabular}

\subsubsection{Interactions between $C N F$ and the hydraulic binders}

A common way to evaluate the influence of the suspended solid on the viscosity of the paste and to sterilize the effects due to the modification of the suspending liquid viscosity is to compare the relative viscosity $\left(\eta_{r}\right)$ which is determined by the ratio of the viscosity of suspensions $\left(\eta_{s}\right)$ to the viscosity of the suspending liquid $\left(\eta_{l}\right)$. Figure 7 presents the relative
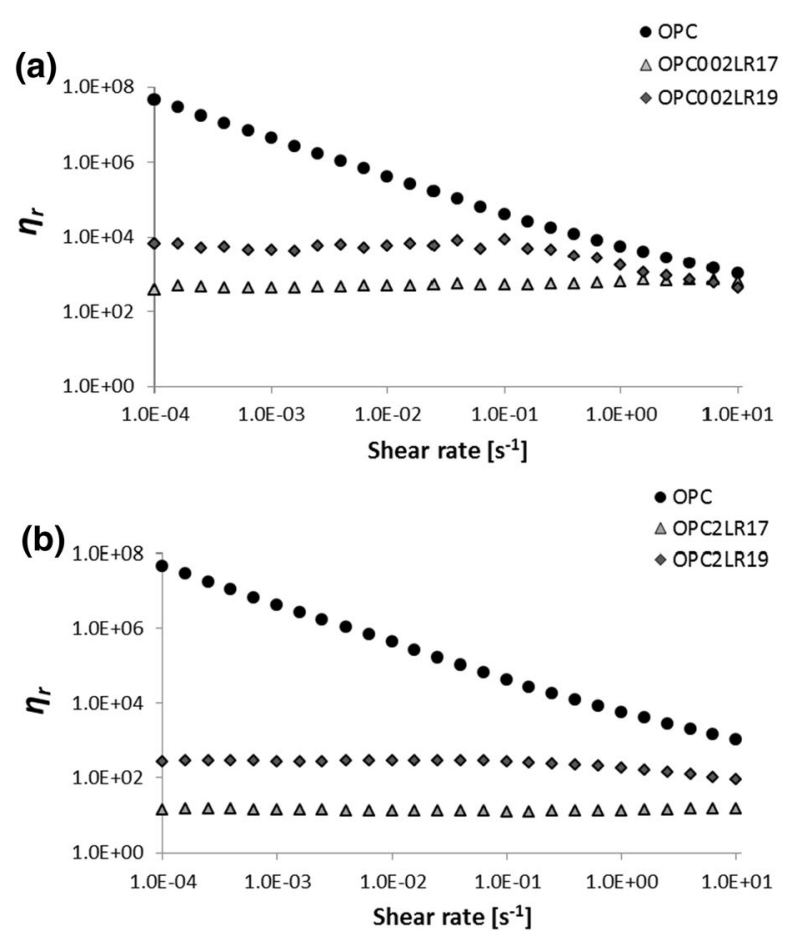

viscosity for OPC and GGBS suspensions in the suspending liquids.

When CNFs are present, either LR17 or LR19, the relative viscosity of the pastes is lower compared to the case when no CNFs are present and the pastes are prepared with water alone. Moreover, it is observed that the $\eta_{r}$ of the suspensions decrease on increasing the dosage of CNFs in the suspending liquid, for both CNFs. The $\eta_{r}$ of suspensions with LR17 in the suspending liquid are significantly lower compared to the ones observed when LR19 is present.

These findings could be explained by the fact that the carboxylic groups introduced by the TEMPO oxidation on the surface of the CNFs may interact with the surface of the particles, either OPC or GGBS. The carboxylic groups can form hydrogen bonds to the particles surface and create a softer shell with a lubrication effect. This reduces the interparticle interaction and friction. The higher $\eta_{r}$ for the suspensions including LR19 (with higher hydrophilic character) may be due to its higher water adsorption as mentioned above (Sect. 3.1.1), leaving less water to disperse the solid particles and lubricate their movement. Alternatively, the LR19 nanofibrils having a larger number of carboxylic groups can promote the formation of
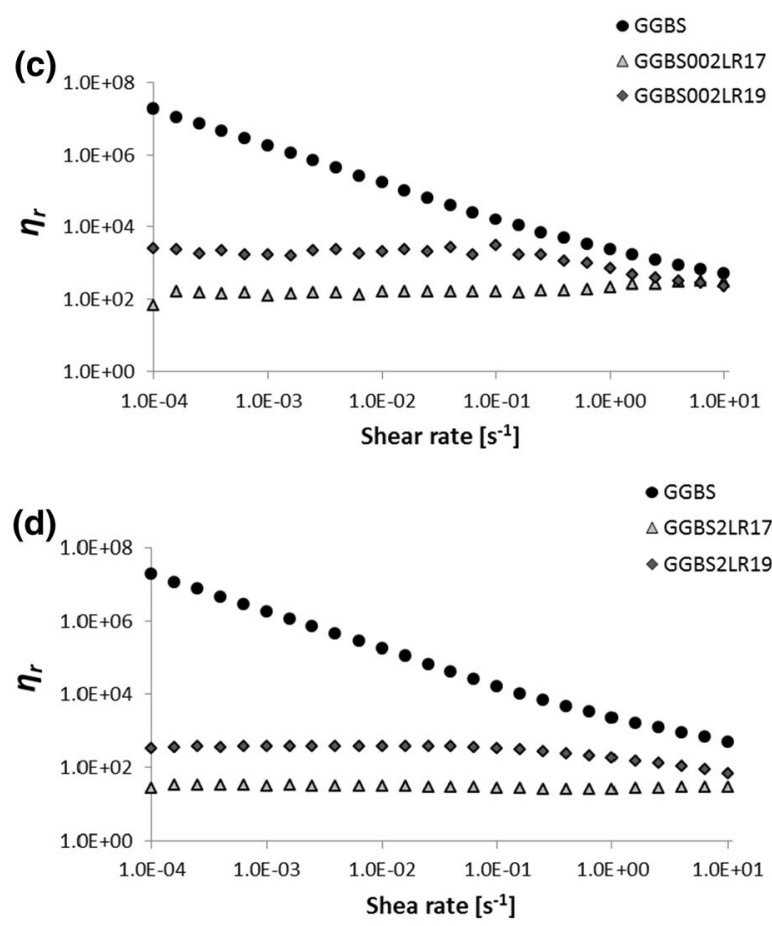

Fig. 7 Relative viscosity of $\mathbf{a}-\mathbf{b}$ OPC and $\mathbf{c}-\mathbf{d}$ GGBS with low and high amount of CNFs 
multiple hydrogen bonds on the surface of individual particles, thus leading to the formation of a hydrogen bonded network [64]. As a conclusion, the presence of the CNFs appears to reduce the interactions among the hydraulic binders' particles, and lubricate the flow of the suspensions.

\subsection{Semi-adiabatic calorimetry}

The hydration heat and heat flux of paste mixtures with $2 \mathrm{wt} \%$ CNFs are shown in Fig. 8 in comparison to the reference without CNFs.

No significant difference for mixtures with or without CNFs is observed for the first heat flux peak occurring just after mixing. At longer times, the presence of CNFs has prolonged the induction dormant period without significantly affecting the hydration heat. This retardation was much more significant in the case of OPC up to 4 and $3 \mathrm{~h}$ in the case of LR17 and LR19, respectively. On the other hand, the addition of CNFs to GGBS showed a slight delay in the heat flow and a minor decrease in the degree of hydration (Fig. 8b, d). The presence of LR17 showed slightly higher hydration of OPC, as confirmed by the cumulative heat release (Fig. 8 c). Such effect has also been noted by $\mathrm{Fu}$ et al. [16]. The retardation of heat flow can be linked to the lower dissolution of the hydrating particles caused by the adsorption of CNFs on their surface. Jiao et al. [17] have shown that the number of active sites for cement dissolution in water decreases with the formation of a hydrophilic complex of calcium ions and carboxyl groups that can adhere to the surface of particles. This effect reduces the surface reactivity of the particles and slows down the hydration rate thus retarding the formation of hydration products at early age.

\subsection{X-ray microtomography}

Images obtained by 3D rendering of 1200 stacked slices are shown in Fig. 9. The 3D images showed a significant difference between the microstructure of samples with and without CNFs. The reference samples of OPC and GGBS displayed a compact microstructure with the appearance of some spherical cavities, mainly in OPC due to the air entrapped during the mixing of the pastes. The addition of $2 \mathrm{wt} \%$ CNFS significantly influenced the microstructure of the matrix as shown by the presence of irregularly shaped features which may likely represent CNF aggregates dispersed within the bulk structure. Such agglomeration of cellulose nanofibrils within the cement matrix had been previously observed by electron microscopy [42]. The tendency of CNF to form aggregates seems to be especially marked: (1) in OPC mixes; (2) in the presence of LR19. Besides, LR19 nanofibrils created weak regions under compression forces, acting as potential stress concentrators leading to the initiation
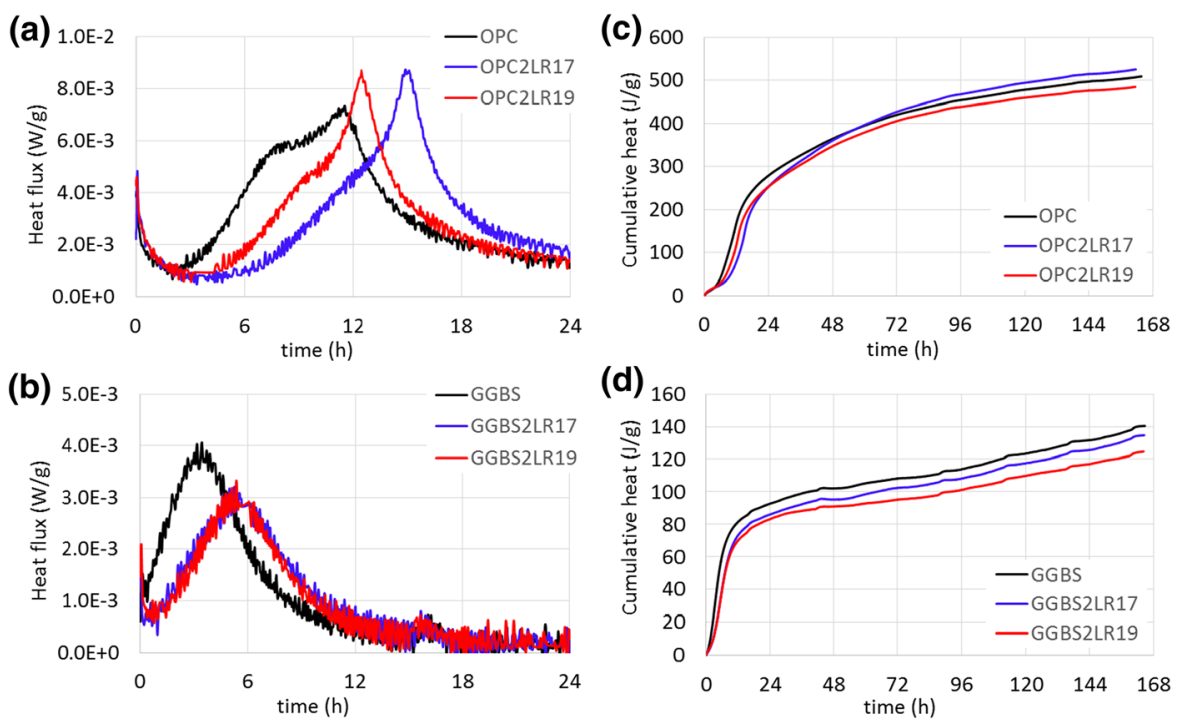

Fig. 8 Heat flux (a-b) and cumulative hydration heat (c-d) of OPC and GGBS with 2 wt $\%$ and without CNFs

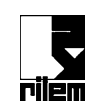




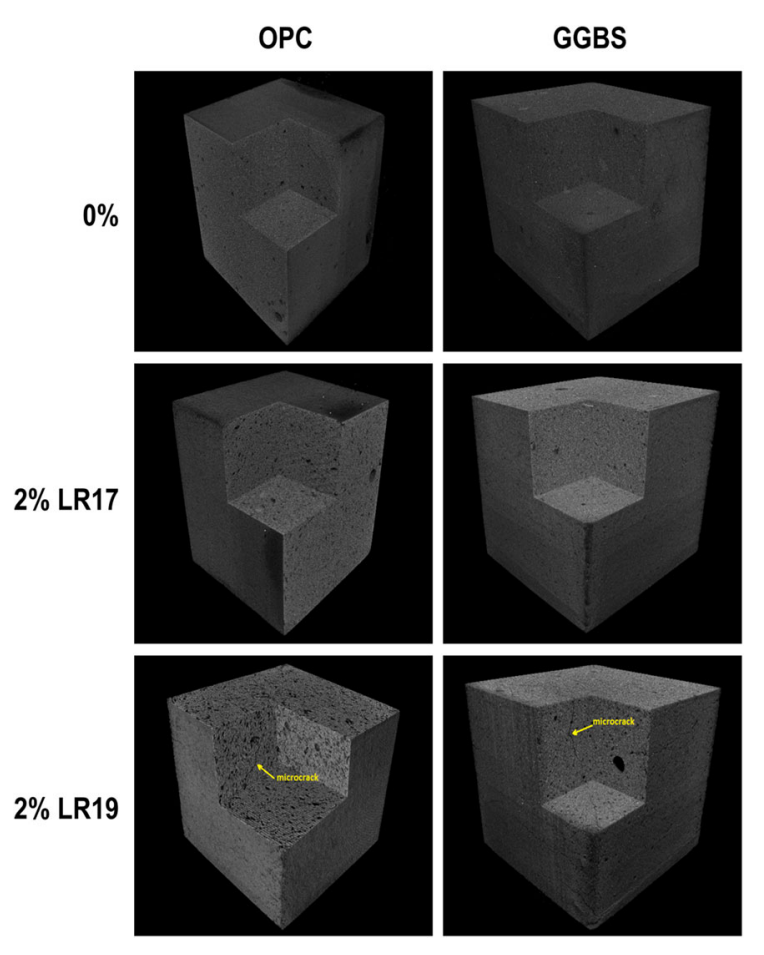

Fig. 9 3D X-ray tomography images of OPC and alkaliactivated GGBS with 2 wt $\%$ and without CNFs obtained after 28 days compressive tests. (The side of the lower faces is approximately $15 \mathrm{~mm}$ in length)

of microcracks within the matrix, which therefore may adversely affect the mechanical performance as shown in the following paragraph.

The final visualization of segmented images is shown in a 2D map (Fig. 10) in which the white pixels represent the sum of air voids and nanofibril aggregates and the dark pixels represent the solid matrix. Due to poor X-ray attenuation contrast, it was not possible to discriminate air voids and CNFs aggregates based on grayscale intensity. The sum of volume $\%$ of air voids and nanofibril aggregates is displayed in Table 5.

It is observed that, in the absence of CNF, the air void volume estimated by tomographic imaging is $<1 \%$ for both the OPC and the GGBS sample. In the presence of $2 \% \mathrm{LR} 17 \mathrm{CNF}$, the volume of lowattenuation features (air voids $+\mathrm{CNF}$ aggregates) increases by a factor 2 for both the OPC and the GGBS sample. When 2\% LR19 CNF is used, the segmented volume increases by a factor of about 3 for the GGBS paste and about 7 for OPC. By comparing these values with the microstructural observation of the 3D

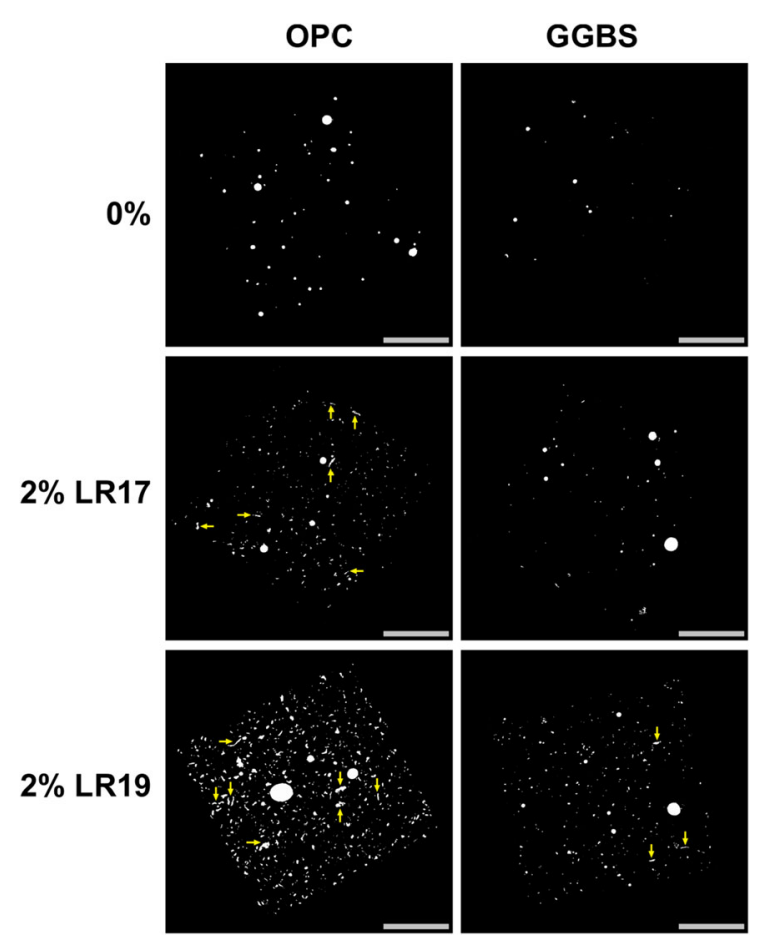

Fig. 10 2D map of OPC and alkali-activated GGBS with $2 \mathrm{wt} \%$ and without CNFs after a binary thresholding and image processing steps, displaying (white pixels) the sum of air voids and CNFs, and (dark pixels) the solid matrix. Yellow arrows pointing to the $\mathrm{CNF}$ aggregates. (The length of the grey scalebar is $5 \mathrm{~mm}$ ). (Color figure online)

Table 5 Estimated volume \% of air voids and nanofibrils in the studied samples

\begin{tabular}{llll}
\hline & Control & 2\%-LR17 & 2\%-LR19 \\
\hline OPC & 0.8 & 1.7 & 5.3 \\
GGBS & 0.4 & 0.8 & 1.4 \\
\hline
\end{tabular}

rendered images (Fig. 9) and 2D sections (Fig. 10) it can be deduced that, for GGBS, the addition of CNF mainly leads to an increase in entrapped air voids, proportionally to the increase in viscosity (LR19 > LR17) since the segmented particles are mostly rounded, with a minor amount of CNF aggregates. For OPC, the volume of segmented objects is equally proportional to the increase in viscosity, but in this case the formation of elongated CNF aggregates seems to play a major role. The tendency of CNF to form aggregates in OPC could be due to different $\mathrm{pH}$ conditions. Previous research has shown that 
entangled nanocellulose aggregates tend to form with decreasing $\mathrm{pH}$, impairing the efficiency of nanofibrillation [65].

The influence of LR19 characteristics as well as its concentration can be clearly noticed. At high concentration, LR19 with higher oxidation degree and hydrophilic behaviour results in a larger water adsorbed layer, causing high swelling ability of nanofibrils as shown by the rheological measurements. This could contribute to the formation of more porous CNFs agglomerates. In other words, the increase of the porous CNFs agglomerates in the cured samples containing higher hydrophilic nanofibrils is due to the excess of water saturation under the moist-curing conditions.

\subsection{Compressive strength}

The compressive strengths of OPC and alkali-activated GGBS pastes with increasing CNF concentrations were determined at 7 and 28 days and the results are shown in Fig. 11. Samples containing LR17 always show higher compressive strength than those containing LR19. For OPC with CNFs, the strength is always lower than the reference without CNFs and it decreases with increasing CNFs dosage. For GGBS, the compressive strength at 7 days decreases with the addition of lower amounts of CNFs $(0.5 \%)$ while this behaviour is not observed with higher CNFs additions (2\%). In any case, the compressive strength at 28 days is recovered. The addition of $2 \%$ LR17 increases the compressive strength at all curing times compared to the reference GGBS.

These findings suggest that the observed variations in compressive strength may results from two competing effects: (1) on the one hand, the increase in air voids (due to larger viscosity) and the formation of CNF aggregates tends to reduce the compressive strength. Since CNF aggregates tend to be loosely entangled, with a large fraction of voids present between individual filaments, they may possibly act as stress concentrators leading to the initiation of microcracks under compressive stresses; (2) on the other hand, well dispersed CNFs may act as fibres to enhance the strength of the material $[15,38]$ e.g. by bridging micro-cracks [66]. In OPC pastes, the increase in air voids and the formation of $\mathrm{CNF}$ aggregates represents the dominating effect and the compressive strength tends to decrease for any CNF addition. On the other hand, an increase in air voids and formation of CNF aggregates seems to be a minor effect in GGBS pastes. The formation of small amounts of additional air voids and CNF aggregates apparently affected the mechanical performance at 7 days, whereas the strengthening effect associated with well dispersed nanofibers became relevant at longer times.

\section{Conclusion}

This study highlights the possibility of developing a suitable pathway for the use of nanofibrils in alkaliactivated slag. Cellulose nanofibrils with two different oxidation degrees were dispersed in water. The effects of dispersed CNFs at $0,0.02,0.5$ and $2 \%$ by weight on the fresh and cured states of alkali-activated slag (GGBS) and ordinary Portland cement (OPC) were examined. Major conclusions of this study are as follows:
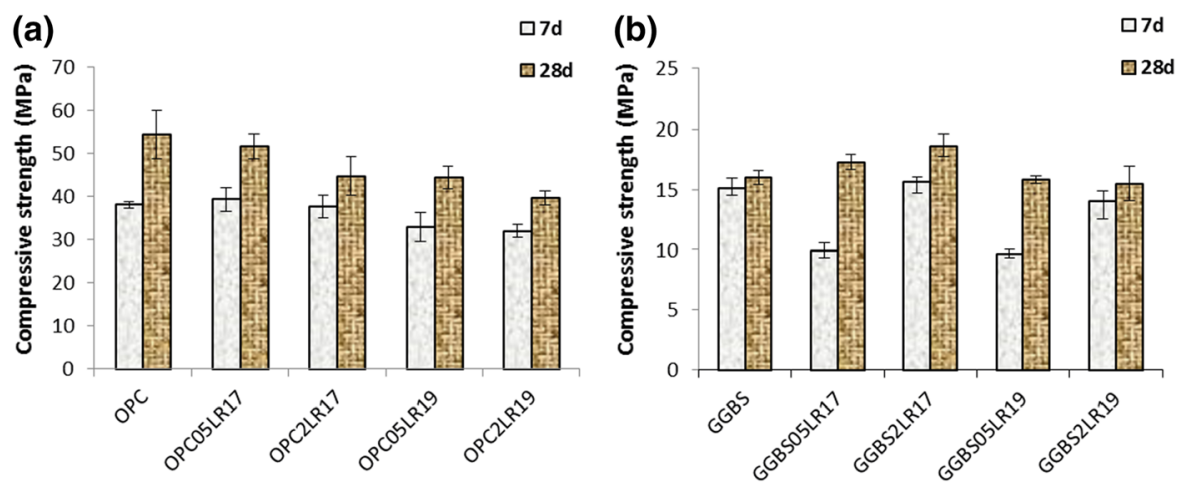

Fig. 11 Compressive strength at 7 and 28 days of OPC a and GGBS b pastes based 0, 0.5 and 2 wt $\%$ CNFs

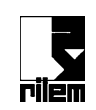


- The rheological measurements showed that the yield stress and viscosity of dispersed CNFs in water can be reduced with higher oxidation degree of nanofibrils. This decrease is attributed to the higher electrostatic repulsion and dispersion of nanofibrils. Moreover, nanofibrils with higher carboxylic group density are capable of adsorbing more water and reducing the inter-fibril interactions. On the contrary, when added to cement or alkali activated GGBS slurries, CNFs appear to reduce the interactions between the hydraulic binders' particles, and lubricate the flow of the suspensions. On the other hand, CNFs can act as a water retention agent and water reservoirs to avoid segregation and bleeding. Further studies are needed to evaluate their effect on dimensional stability of hardened specimens.

- CNFs have no significant effect on the hydration heat of hydraulic binders at early age. A slight retardation can be observed at later ages due to lower dissolution of the hydraulic binders' particles caused by the adsorption of nanofibrils on their surface.

- Based on the X-ray tomography analysis, the use of nanofibrils with high oxidation degree apparently leads to a higher increase in the formation of CNF aggregates (and, secondarily, to an increase of air voids) than the use of low oxidation degree CNF. This agrees with both the observed larger viscosity achieved by the mixes with LR19 and with the lower compressive strengths observed in the presence of LR19 as compared to LR17. Compared to OPC, the volume of air voids and CNF aggregates in GGBS does not increase as much when CNF is added. This also agrees with the comparatively smaller effect observed for compressive strength.

- When CNFs are present, the high porosity lowers the compressive strengths of OPC pastes. This decrease was related to the swelling ability of high fraction nanofibrils creating internal water reservoirs, and to their self-aggregation that can behave as potential stress concentrators leading to the initiation of microcracks under compression forces. The CNFs effect on GGBS pastes is more complex and deserves further investigation. Moreover, further studies are planned to assess the impact of CNFs on the tensile strength.
Acknowledgements L.R. and C.P. thanks InnovhubStazioni Sperimentali per l'Industria s.r.l. - Area Carta, Cartoni e Paste per Carta for financial support. We also thank professors Giovanni Dotelli and Paola Gallo Stampino of Politecnico di Milano for having supported the collaboration with the University of Padova.

Funding Open Access funding provided by Università degli Studi di Padova. Open Access funding provided by Università degli Studi di Padova.

\section{Compliance with ethical standards}

Conflict of interest There are no conflicts of interest in this work.

Open Access This article is licensed under a Creative Commons Attribution 4.0 International License, which permits use, sharing, adaptation, distribution and reproduction in any medium or format, as long as you give appropriate credit to the original author(s) and the source, provide a link to the Creative Commons licence, and indicate if changes were made. The images or other third party material in this article are included in the article's Creative Commons licence, unless indicated otherwise in a credit line to the material. If material is not included in the article's Creative Commons licence and your intended use is not permitted by statutory regulation or exceeds the permitted use, you will need to obtain permission directly from the copyright holder. To view a copy of this licence, visit http://creativecommons.org/licenses/by/4.0/.

\section{References}

1. Purdon AO (1940) The action of alkalis on blast-furnace slag. J Soc Chem Ind 59:191-202

2. Buchwald A, Vanooteghem M, Gruyaert E et al (2015) Purdocement: application of alkali-activated slag cement in Belgium in the 1950s. Mater Struct 48:501-511. https://doi. org/10.1617/s11527-013-0200-8

3. Shi C (2003) Corrosion resistance of alkali-activated slag cement. Adv Cem Res 15:77-81. https://doi.org/10.1680/ adcr.2003.15.2.77

4. Madhuri K, Srinivasa Rao G (2018) Performance of alkaliactivated slag concrete against sulphuric acid attack. Asian J Civ Eng. 19:451-461. https://doi.org/10.1007/s42107-0180028-1

5. Aula M, Haapakangas J, Heikkilä A, Iljana M, Kemppainen A, Roininen J, Sulasalmi P, Visuri V-V (2012) Some environmental aspects of BF, EAF and BOF, University of Oulu, Faculty of Technology, Department of Process and Environmental Engineering (2012), ISBN 978-951-429832-5

6. Das B, Prakash S, Reddy PSR, Misra VN (2007) An overview of utilization of slag and sludge from steel industries. Resour Conserv Recycl 50:40-57. https://doi.org/10.1016/j. resconrec.2006.05.008

7. Walling SA, Bernal SA, Gardner LJ, Kinoshita H, Provis J (2018) Blast furnace slag- $\mathrm{Mg}(\mathrm{OH}) 2$ cements activated by 
sodium carbonate. RSC Adv 8:23101-23118. https://doi. org/10.1039/c8ra03717e

8. Shi PKC, Roy D (2003) Alkali-Activated Cements and Concretes, 1st edn. CRC Press, London. https://doi.org/10. 1201/9781482266900

9. Bernal SA, Provis JL, Fernández-jiménez A, Krivenko PV, Kavalerova E, Palacios M, Shi C (2014) Alkali activated materials. Springer, Netherlands. https://doi.org/10.1007/ 978-94-007-7672-2

10. Provis JL, Bernal SA (2014) Geopolymers and related alkali-activated materials. Annu Rev Mater Res 44:299-327. https://doi.org/10.1146/annurev-matsci070813-113515

11. Awoyera P, Adesina A (2019) A critical review on application of alkali activated slag as a sustainable composite binder. Case Stud Constr Mater. https://doi.org/10.1016/j. cscm.2019.e00268

12. Garcia-Lodeiro I, Palomo A, Fernández-Jiménez A (2015) Crucial insights on the mix design of alkali-activated cement-based binders. Woodhead Publishing Limited, Cambridge. https://doi.org/10.1533/9781782422884.1.49

13. Palacios M, Puertas F (2005) Effect of superplasticizer and shrinkage-reducing admixtures on alkali-activated slag pastes and mortars. Cem Concr Res 35:1358-1367. https:// doi.org/10.1016/j.cemconres.2004.10.014

14. Palacios M, Houst YF, Bowen P, Puertas F (2009) Adsorption of superplasticizer admixtures on alkali-activated slag pastes. Cem Concr Res 39:670-677. https://doi. org/10.1016/j.cemconres.2009.05.005

15. Mejdoub R, Hammi H, Suñol JJ, Khitouni M, A. M'nif, S. Boufi, (2017) Nanofibrillated cellulose as nanoreinforcement in Portland cement: thermal, mechanical and microstructural properties. J Compos Mater 51:2491-2503. https://doi.org/10.1177/0021998316672090

16. Fu T, Moon RJ, Zavattieri P, Youngblood J, Weiss WJ (2017) Cellulose nanomaterials as additives for cementitious materials. Elsevier Ltd, Amsterdam. https://doi.org/ 10.1016/B978-0-08-100957-4.00020-6

17. Jiao L, Su M, Chen L, Wang Y, Zhu H, Dai H (2016) Natural cellulose nanofibers as sustainable enhancers in construction cement. PLoS ONE 11:1-13. https://doi.org/10.1371/ journal.pone.0168422

18. Parveen S, Rana S, Fangueiro R, Paiva MC (2017) A novel approach of developing micro crystalline cellulose reinforced cementitious composites with enhanced microstructure and mechanical performance. Cem Concr Compos 78:146-161. https://doi.org/10.1016/j. cemconcomp.2017.01.004

19. Zhai L, Kim HC, Kim JW, Kang J, Kim J (2018) Elastic moduli of cellulose nanofibers isolated from various cellulose resources by using aqueous counter collision. Cellulose 25:4261-4268. https://doi.org/10.1007/s10570-018-1836-x

20. Moon RJ, Martini A, Nairn J, Simonsen J, Youngblood J (2011) Cellulose nanomaterials review: structure, properties and nanocomposites. Chem Soc Rev. https://doi.org/10. 1039/c0cs00108b

21. Tarrés Q, Boufi S, Mutjé P, Delgado-Aguilar M (2017) Enzymatically hydrolyzed and TEMPO-oxidized cellulose nanofibers for the production of nanopapers: morphological, optical, thermal and mechanical properties. Cellulose 24:3943-3954. https://doi.org/10.1007/s10570-017-1394-7
22. Sun X, Wu Q, Lee S, Qing Y, Wu Y (2016) Cellulose nanofibers as a modifier for rheology, curing and mechanical performance of oil well cement. Sci Rep 6:1-9. https:// doi.org/10.1038/srep31654

23. Tang Z, Huang R, Mei C, Sun X, Zhou D, Zhang X, Wu Q (2019) Influence of cellulose nanoparticles on rheological behavior of oilwell cement-water slurries. Materials (Basel) 12:1-14. https://doi.org/10.3390/ma12020291

24. Chakraborty S, Kundu SP, Roy A, Adhikari B, Majumder SB (2013) Effect of jute as fiber reinforcement controlling the hydration characteristics of cement matrix. Ind Eng Chem Res 52:1252-1260. https://doi.org/10.1021/ ie $300607 \mathrm{r}$

25. Sun X, Wu Q, Ren S, Lei T (2015) Comparison of highly transparent all-cellulose nanopaper prepared using sulfuric acid and TEMPO-mediated oxidation methods. Cellulose 22:1123-1133. https://doi.org/10.1007/s10570-015-0574-6

26. Fukuzumi H, Saito T, Isogai A (2013) Influence of TEMPOoxidized cellulose nanofibril length on film properties. Carbohydr Polym 93:172-177. https://doi.org/10.1016/j. carbpol.2012.04.069

27. Missoum K, Belgacem MN, Bras J (2013) Nanofibrillated cellulose surface modification: a review. Materials (Basel) 6:1745-1766. https://doi.org/10.3390/ma6051745

28. Tang Z, Li W, Lin X, Xiao H, Miao Q, Huang L, Chen L, Wu H (2017) TEMPO-Oxidized cellulose with high degree of oxidation. Polymers (Basel) 9:3-4. https://doi.org/10. 3390/polym9090421

29. Isogai A, Saito T, Fukuzumi H (2011) TEMPO-oxidized cellulose nanofibers. Nanoscale 3:71-85. https://doi.org/10. 1039/c0nr00583e

30. Saito T, Kimura S, Nishiyama Y, Isogai A (2007) Cellulose nanofibers prepared by TEMPO-mediated oxidation of native cellulose. Biomacromol 8:2485-2491. https://doi. org/10.1021/bm0703970

31. Lasseuguette E, Roux D, Nishiyama Y (2008) Rheological properties of microfibrillar suspension of TEMPO-oxidized pulp. Cellulose 15:425-433. https://doi.org/10.1007/ s10570-007-9184-2

32. Okita Y, Saito T, Isogai A (2010) Entire surface oxidation of various cellulose microfibrils by TEMPO-mediated oxidation. Biomacromol 11:1696-1700. https://doi.org/10.1021/ bm100214b

33. Saito T, Hirota M, Tamura N, Kimura S, Fukuzumi H, Heux L, Isogai A (2009) Individualization of nano-sized plant cellulose fibrils by direct surface carboxylation using TEMPO catalyst under neutral conditions. Biomacromol 10:1992-1996. https://doi.org/10.1021/bm900414t

34. Saito T, Nishiyama Y, Putaux JL, Vignon M, Isogai A (2006) Homogeneous suspensions of individualized microfibrils from TEMPO-catalyzed oxidation of native cellulose. Biomacromol 7:1687-1691. https://doi.org/10. 1021/bm060154s

35. Jönsson B, Wennerström H, Nonat A, Cabane B (2004) Onset of cohesion in cement paste. Langmuir 20:6702-6709. https://doi.org/10.1021/la0498760

36. Lesko S, Lesniewska E, Nonat A, Mutin JC, Goudonnet JP (2001) Investigation by atomic force microscopy of forces at the origin of cement cohesion. Ultramicroscopy 86:11-21. https://doi.org/10.1016/S0304-3991(00)00091-7 
37. Isabelle ANP, Plassard C, Lesniewska E, Labbez C, Jönsson B (2007) Nanoscale investigation of particle interactions at the origin of the cohesion of cement. In: Proceedings of the 12 th international congress on the chemistry of cement, Montreal

38. Balea A, Fuente E, Blanco A, Negro C (2019) Nanocelluloses: natural-based materials for fiber-reinforced cement composites. A critical review. Polymers (Basel). https://doi. org/10.3390/polym11030518

39. Sun X, Wu Q, Zhang J, Qing Y, Wu Y, Lee S (2017) Rheology, curing temperature and mechanical performance of oil well cement: combined effect of cellulose nanofibers and graphene nano-platelets. Mater Des 114:92-101. https://doi.org/10.1016/j.matdes.2016.10.050

40. Ahmad D, van den Boogaert I, Miller J, Presswell R, Jouhara H (2018) Hydrophilic and hydrophobic materials and their applications. Energy Sources Part A Recover Util Environ Eff 40:2686-2725. https://doi.org/10.1080/ 15567036.2018.1511642

41. Ardanuy M, Claramunt J, García-Hortal JA, Barra M (2011) Fiber-matrix interactions in cement mortar composites reinforced with cellulosic fibers. Cellulose 18:281-289. https://doi.org/10.1007/s10570-011-9493-3

42. Hisseine OA, Omran AF, Tagnit-Hamou A (2018) Influence of cellulose filaments on cement paste and concrete. J Mater Civ Eng 30:1-14. https://doi.org/10.1061/(ASCE)MT. 1943-5533.0002287

43. Knill CJ, Kennedy JF (2002) Degradation of cellulose under alkaline conditions. Carbohydr Polym 51:281-300. https:// doi.org/10.1016/S0144-8617(02)00183-2

44. Segal L, Creely JJ, Martin AE, Conrad CM (1959) An empirical method for estimating the degree of crystallinity of native cellulose using the X-ray diffractometer. Text Res J 29:786-794. https://doi.org/10.1177/ 004051755902901003

45. Park S, Baker JO, Himmel ME, Parilla PA, Johnson DK (2010) Cellulose crystallinity index: measurement techniques and their impact on interpreting cellulase performance. Biotechnol Biofuels 3:1-10. https://doi.org/10. 1186/1754-6834-3-10

46. Wulandari WT, Rochliadi A, Arcana IM (2016) Nanocellulose prepared by acid hydrolysis of isolated cellulose from sugarcane bagasse. IOP Conf Ser Mater Sci Eng. https://doi. org/10.1088/1757-899X/107/1/012045

47. Xu X, Liu F, Jiang L, Zhu JY, Haagenson D, Wiesenborn DP (2013) Cellulose nanocrystals vs. cellulose nanofibrils: a comparative study on their microstructures and effects as polymer reinforcing agents. ACS Appl Mater Interfaces 5:2999-3009. https://doi.org/10.1021/am302624t

48. Bellotto M, Dalconi MC, Contessi S, Garbin E, Artioli G (2019) Formulation, performance, hydration and rheological behavior of 'just add water' slag-based binders. In: Proceedings of the first international conference on innovation in low-carbon cement and concrete technology, pp 3-6.

49. Provis JL (2018) Alkali-activated materials. Cem Concr Res 114:40-48. https://doi.org/10.1016/j.cemconres.2017.02. 009

50. Valentini L, Contessi S, Dalconi MC, Zorzi F, Garbin E (2018) Alkali-activated calcined smectite clay blended with waste calcium carbonate as a low-carbon binder. J Clean
Prod 184:41-49. https://doi.org/10.1016/j.jclepro.2018.02. 249

51. Feldkamp LA (1984) Practical cone-beam algorithm Sfrdr I _f. America (NY) 1:612-619

52. Morgavi D, Valentini L, Porreca M, Zucchini A, Di Michele A, Ielpo M, Costa A, Rossi S, Landi P, Perugini D (2018) Volcanic ash aggregation enhanced by seawater interaction: the case of the Secche Di Lazzaro phreatomagmatic deposit (stromboli). Ann Geophys 61:1-18. https://doi.org/10.4401/ ag-7874

53. Schindelin J, Arganda-Carreras I, Frise E, Kaynig V, Longair M, Pietzsch T, Preibisch S, Rueden C, Saalfeld S, Schmid B, Tinevez JY, White DJ, Hartenstein V, Eliceiri K, Tomancak P, Cardona A (2012) Fiji: an open-source platform for biological-image analysis. Nat Methods 9:676-682. https://doi.org/10.1038/nmeth.2019

54. Huang LK, Wang MJJ (1995) Image thresholding by minimizing the measures of fuzziness. Pattern Recognit 28:41-51. https://doi.org/10.1016/0031-3203(94)E0043-K

55. E.C. for Standardization (2005) EN 196-1: methods of testingcement-part 1: determination of strength

56. Panizza M, Natali M, Garbin E, Ducman V, Tamburini S (2020) Optimization and mechanical-physical characterization of geopolymers with construction and demolition waste (CDW) aggregates for construction products. Constr Build Mater 264:120158. https://doi.org/10.1016/j. conbuildmat.2020.120158

57. Rao MA (2007) Rheology of fluid and semisolid foods: principles and applications, 2nd edn. Springer, Boston. https://doi.org/10.1007/978-0-387-70930-7

58. Shenoy AV (1999) Rheology of filled polymer systems, 1st edn. Springer, Pune. https://doi.org/10.1007/978-94-0159213-0

59. Dimens M (1906) A new determination of molecular. Ann Phys 19(4):317-381, (19:289-306, 1911)

60. Krieger IM, Dougherty TJ (1959) A mechanism for nonnewtonian flow in suspensions of rigid spheres. Trans Soc Rheol 3:137-152. https://doi.org/10.1122/1.548848

61. Wessel R, Ball RC (1992) Fractal aggregates and gels in shear flow. Phys Rev A 46:3008-3011. https://doi.org/10. 1103/PhysRevA.46.R3008

62. Shi D, Ye J, Zhang W (2020) Effects of activator content on properties, mineralogy, hydration and microstructure of alkali-activated materials synthesized from calcium silicate slag and ground granulated blast furnace slag. J Build Eng 32:101791. https://doi.org/10.1016/j.jobe.2020.101791

63. Vance K, Dakhane A, Sant G, Neithalath N (2014) Observations on the rheological response of alkali activated fly ash suspensions: the role of activator type and concentration. Rheol Acta 53:843-855. https://doi.org/10.1007/ s00397-014-0793-z

64. Hojczyk OWM (2011) Melt-rheological behavior of highsolid cement-in-polymer dispersions. J Appl Polym Sci 119:565-571. https://doi.org/10.1002/app.32676

65. Park JY, Park CW, Han SY, Kwon GJ, Kim NH, Lee SH (2019) Effects of $\mathrm{pH}$ on nanofibrillation of TEMPO-oxidized paper mulberry bast fibers. Polymers (Basel). https:// doi.org/10.3390/polym11030414

66. Claramunt J, Ventura H, Toledo Filho RD, Ardanuy M (2019) Effect of nanocelluloses on the microstructure and mechanical performance of CAC cementitious matrices. 
Cem Concr Res 119:64-76. https://doi.org/10.1016/j. cemconres.2019.02.006
Publisher's Note Springer Nature remains neutral with regard to jurisdictional claims in published maps and institutional affiliations. 